\title{
The Management of the Burned Child
}

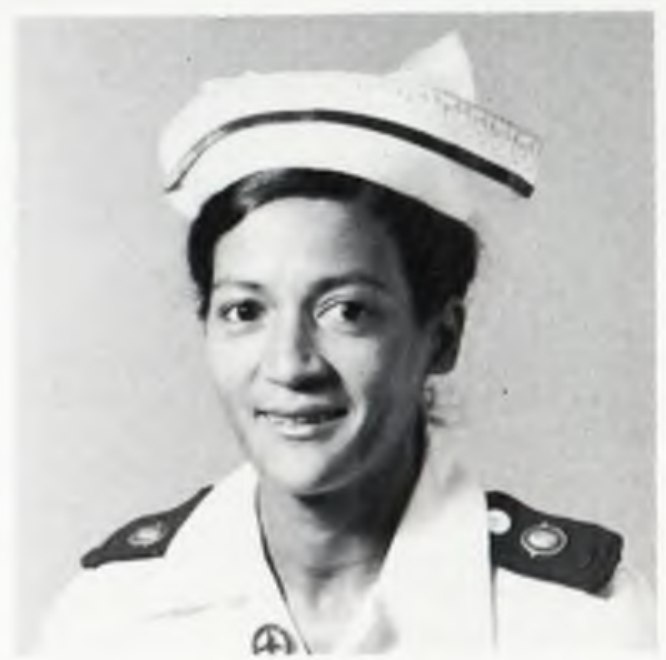

L.N. Amon, R.G.N., R.M., Diploma Paediatric Nursing

Senior Sister, Red Cross War Memorial Children's Hospital, Rondebosch, Cape Town.

\section{OPSOMMING}

Die feit dat daar elke jaar 'n gemiddelde van 540 kinders met matige tot ernstige brand wonde opgeneem moet word, het daartoe gelei dat daar 'n doeltreffende behandelingsprogram in 'n spesiale sorgsaal van 30 beddens by die Rooikruis-Oorlogsgedenkhospitaal vir Kinders aan die gang gesit is. Hierdie syfer beklemtoon die omvattende probleem waarvoor die gemeenskap i.v.m. die voorkoming van sulke beserings te staan kom en die probleem om 'n oplossing te vind vir die beveiliging van kinders teen trauma wat hulle vir die res van hulle lewe kan skend of belemmer.

T HE need to admit an average of 540 children each year with moderate to severe degree burn injuries has led to the development of an effective treatment programme in a 30-bed special care ward at the Red Cross War Memorial Children's Hospital, Rondebosch. These numbers highlight the extensive problem facing the community in the prevention of such injuries, and in finding a way to safeguard children against trauma that can disfigure or handicap them for life.

A burn injury, one which can profoundly change the lives of many people, is the result of an accident which can happen in the best of families. We find, however, that most of our patients tend to come from the lower income groups where social problems such as overcrowding, or young children left in the care of older siblings are common factors. These problems are often compounded by ignorance.

\section{THE MAIN CAUSES OF BURNS}

1. Hot or Boiling Liquids: Very common in the 9 months to 3-year age group. At this stage the child is developing an inquisitiveness and a need to explore his environment which leads to his plucking at or pulling on things such as tablecloths or the cord of an electric kettle. The bums are usually caused by hot water, tea, coffee, soup or milk.
2. Fire Burns: These are commoner in the 6 to 12 year age group, the cause frequently being a exploding primus stoves, clothing ignited by children playing with matches, or the striking of matches in abandoned cars.

3. Electrical Burns: are caused by children accidentally coming in contact with electrically charged "live" wires.

4. Chemical Burns: are rare in the paediatric age group and we seldom see them in our unit.

\section{STATISTICS}

During a five year period - 1970-1974 a total of 2118 new patients were admitted to our burns unit. There were 35 deaths (mortality rate $1,6 \%$ ). This low rate is in part due to the fact that most of the patients had burns of a relatively minor nature. An assessment of the severity of the thermal injuries treated in the unit was obtained from an analysis of 931 patients admitted over a 2-year period - 1973 - 1974. Of this group 585 (63\%) had partial thickness burns i.e. burns involving epidermis and dermis, $670(72 \%)$ had burns involving less than $9 \%$ of the total body surface area while only 5 patients $(0,5 \%)$ had burns greater than $50 \%$ of the body surface area. During this 2 -year period, the cause of burning in 680 patients (73\%) was hot liquid while 228 $(25 \%)$ were fire burns. In contrast during the 5-year period $(1970-174) 29(83 \%)$ of the 35 patients who died had 
burns caused by fire and $6(17 \%)$ had burns caused by hot liquid. This analysis gives a better perspective of the overall mortality rate for the whole period under discussion and emphasises the grave nature of fire burns.

\section{Criteria for Admission}

A. All burns involving

(a) $5 \%$ or more of the body surface in infants under 2 years.

(b) $10 \%$ or more of the body surface in older children.

B. (a) All patients where the possibility of inhalation burns exists.

(b) Circumferential burns of limbs which may cause vascular impairment and chest burns which may impede respiratory movements.

(c) Electrical burns.

(d) Burn wounds less than $10 \%$ in extent but which involve the face, hands or feet.

(e) Difficult areas such as perineum or flexure surfaces.

(f) Septic or neglected burns.

\section{THE UNIT}

At Red Cross Childrens' Hospital patients with thermal injury are admitted to a 30-bed special care unit. The unit is airconditioned to provide environmental temperature control which is maintained at $27^{\circ} \mathrm{C}$ in winter and at $23^{\circ} \mathrm{C}$ in summer. Single cubicles are used for children with major burns while 4 larger cubicles are used for cases of

(a) Minor fresh burns

(b) Post-operative patients

(c) Septic wounds

(d) Convalescent patients.

As the majority of burns occur during the winter months, bed occupancy during this period is due mainly to fresh bums while during the summer months, a percentage of the beds are allocated for plastic surgery in children with old burn scars. The ward is staffed by 3 registered nurses and 4 staff nurses, 13 enrolled assistant nurses on day duty and 1 staff nurse and 7 assistant nurses on night duty. There is accommodation for up to 30 patients although during winter months this number may be exceeded. Every effort is made to create a pleasant unstressed atmosphere both for its psychological effect on the patients and because of its positive effect in ensuring efficient teamwork.

\section{TREATMENT ON ADMISSION}

\section{Reassure patient and relieve pain}

In major bums morphine is given. while those with minor burns receive a combination of Ponstan - (analgesic) and Vallergan - (sedative).

Care must be taken not to sedate too deeply especially in the presence of clinical shock. when septicaemia is suspected or in the presence of a full stomach.

\section{Control of Infection}

Wound and throat swabs are taken. All patients are given tetanus toxoid and gamma globulin. Bicillin is given as a single intramuscular dose with oral pencillin continued for one week as a prophylactic measure.

\section{Control of Burn Shock}

If the burn is greater than $5 \%$ of the body surface in the under 2-year old child and over 10\% in the older child, plasma is administered intravenously:

The following formula is used to determine the amount of intravenous plasma to be administered:-

$3,5 \mathrm{ml} \times \%$ bum area $\mathrm{x}$ weight in kilograms.

When using the above formula it is important that the " $\%$ Burn area" used in the calculation does not exceed the following percentages:

$20 \%$ in $0-2$ year old child

$25 \%$ in 3 - 7 -year old child

$30 \%$ in $8-15$-year old child.

The calculated volume of plasma is given in three divided amounts over a period of 36 hours. The calculation is used merely as a guideline with packed cell volume determination as a further guide to volume replacement.

\section{SPECIAL OBSERVATIONS FOR MAJOR BURNS:}

1. Because the development of a paralytic ileus - so called "burn ileus" - is common and can be a deadly complication, the patient is kept off all intake by mouth for at least $12-24$ hours. A naso-gastric tube is passed to decompress the stomach.

2. Maintenance fluids are given intravenously.

3. An indwelling urinary catheter is inserted to allow for accurate assessment of urinary output. The specific gravity of all urine passed is measured as an indication of the kidneys-concentrating ability.

4. Very strict monitoring and recording of temperature, pulse, respiration. blood pressure, fluid intake and urinary output are of vital importance.

5. Monitoring of haemoglobin levels is required as the destruction of red blood cells usually necessitates the administration of whole blood in the last phase of the intravenous resuscitation regime.

6. If the patient develops hyperpyrexia a blood culture is done.

7. A test for urinary fluorescence is done towards the 2 nd week of burn management. A positive result is an early sign of pseudomonas septicaemia and treatment can thus be commenced even before a positive blood culture result is obtained.

\section{WOUND MANAGEMENT}

This can be either early skin grafting or the application of creams.

\section{A. Harly Grating}

This is usually done within the first 7 days post-trauma while there is minimal organismal contamination of the wound. The patients selected for early grafting must be fully resuscitated and free of infection especially caused by beta haemolvtic streptococcus, pseudomonas or resistant strains of the staphvlococrus aureus.

\section{Advantages of early grafting}

1. Risk of infection reduced. 
2. Facilitates early restoration of function which is especially important in the case of hands.

3. It shortens the patient's stay in hospital which has several important results viz. it lessens the break in the mother/child relationship and the break in schooling, as well as reducing the hospital expenses, thereby helping the family economy.

\section{B. Application of Creams}

Everything hinges on asepsis. All burns are nursed using the closed method which facilitates nursing care. The older children can become ambulant at an earlier stage and the smaller children can be picked up and be cuddled and comforted.

Patients are sedated before the dressings are applied. The creams used are:

(1)Betadine which is an iodine-based antiseptic cream and is effective for 24 hours. Although it has poor tissuepenetration it does not impair epithelial regeneration. It is used as a prophylaxis against bacterial contamination of wounds.

(2)Silver Sulphadiazine (Flamazine) is an antibiotic cream which is effective for 24 hours. It is used as a prophylactic application for the initial treatment of the uncontaminated burn or for the treatment of those burns contaminated by Gram-negative organisms. Contamination by staphylococcus aureus is poorly controlled by this cream.

(3)Sulphamylon $10 \%$. This antibiotic cream is effective for only 12 hours. It has good eschar-penetration and is effective in the treatment of gram-negative wound infections. Unfortunately the cream stings on application and has a tendency to cause metabolic acidosis. The blood $\mathrm{pH}$ is therefore carefully monitored when this cream is used. Because of this tendency to alter blood $\mathrm{pH}$ it is never used in the presence of impaired pulmonary function.

C. Wound cultures are repeated weekly - or more frequently in major burns.

\section{Dressing Room Technique}

Nurses allocated to the dressing room wear caps, gowns and masks. Sterile disposable gloves are worn and changed for each dressing. Some patients are bathed to aid in the debridement of wounds using a Betadine solution $(1-100)$.

\section{Post-Operative Care}

In theatre the grafted area and donor area are covered by a layer of Tullegras, Betadine and acriflavine. These dressings are left in position for $4-5$ days.

\section{Types of Grafts}

1. Autograft, using the patient's own skin, will give permanent coverage and is usually meshed to be allowed for drainage. In major burns the meshing technique allows for the graft to be stretched to cover a larger area.

As many of the major burns do not have enough donor areas, an alternative temporary cover has to be provided to reduce the size of the wound and to provide a good granulation bed for autografting when previously used donor sites have healed and are more available. These are:-

Homografts: Skin from another person

Xenografts: e.g. "Pig"' skin

Synthetic Substitutes - Opsite

\section{Prevention of Hypertrophic Scarring}

Once the burned area has been grafted and the scars show a tendency to hypertrophy the occupational therapist will have the patient measured for a pressure garment, which is made of an elastic material. This garment must be worn continually. It is only removed for bathing or for the application of lanoline. The garment must fit snugly and is worn with the seams on the outside to prevent irritation of the sensitive skin. It is very effective in reducing hypertrophic scarring, keeps the skin soft and prevent itchiness. For the best results the garment should be worn for at least six months to I year.

\section{Prevention of Contractures}

Physiotherapists and occupational therapists play a major role in the treatment of burns. The patient requires a great deal of encouragement and a clear explanation as to why physiotherapy is as necessary for his recovery as medications and grafting. Physiotherapy starts on admission by positioning the patient correctly e.g. extension of the neck in burns involving this area. Initially physiotherapy consists of passive movements of the joints through one full range of movement at least once a day. As healing progresses the physiotherapy becomes active i.e. the patient then participates in the movements and exercises of the affected limbs.

Splinting may also be required to maintain the maximum range of movements in the joints susceptible to contractures or maintain the range of movement gained through exercise. Splinted limbs should be checked frequently for pressure, possible circulatory impairment and swelling. Early ambulation and exercises in the form of play remain the best forms of physiotherapy.

\section{PREVENTION AND CONTROL OF INFECTION}

This begins on admission and continues until the patient is discharged with very special precautions being taken until the burnt area is fully grafted. This can only be achieved by the full co-operation of all members of the staff. Staff must be made aware of the fact that infection in a burn wound can be lethal. With this object in view the following points are stressed:

1. Thorough and frequent hand-washing with an antiseptic lotion is mandatory.

2. Masks are to be worn by everyone entering the unit.

3. Special cubicles are set aside for fresh burns and pre- and post-operative cases.

4. Patients with infected wounds are isolated in a cubicle at the end of the ward. Nurses allocated to this cubicle do not work in any other area of the ward.

5. No soap is used on the unit as it has the potential to harbour pseudomonas organisms.

6. Throat swabs of all staff are taken monthly. 
7. Disposable linen and eating utensils are used.

8. Toys used must, later, either be discarded or sterilized, if this is feasible.

\section{NUTRITIONAL SUPPORT}

To promote healing the patient must be maintained in a good nutritional state. Adequate protein and extra kilojoules are necessary, to regenerate destroyed tissue which results in an increased metabolic rate. Eggs are used as the main source of protein replacement as they are easily assimilated, cheap and can be served in a variety of ways. A child with a major burn may require up to 20 eggs a day. Oral fluids are given at 2-hourly intervals and may consist of High Calorie Milk, Milo, Hycal and fresh orange juice. Vitamin supplements are given.

In major burns intravenous vein alimentation with Travasol - (an amino acid solution) - and Intralipid also play a major role in improving the nutritional state of the child.

\section{PSYCHOLOGICAL SUPPORT AND REHABILITATION}

The goal of rehabilitation is to help the child to devlop to his maximum potential within the limits of his disability. This includes helping the child and his parents to accept disfiguring scars and any handicaps with which he may be left.

The response of the child and his parents to his trauma varies in every case. Because of the intense fright caused by the accident and subsequent admission to hospital, he needs constant reassurance, company and occupation. The child may also have quite intense guilt feelings if his injury was caused by some activity forbidden by his parents or against which they had warned him.

Because of the fright, pain and the separation from his parents and family, a child with major burns may become very depressed. He must be encouraged to overcome his depression and aggression through the medium of play if he cannot do so verbally. He should be encouraged to express his feelings and to cry if he feels homesick or finds the procedure distressing. A nurse with whom the patient has established a trusting relationship, should be with him at such times as her presence will help him to endure the periods of stress and pain. Being able to express his emotions will help him firstly to adjust to his trauma and secondly to prepare him for his subsequent return to his family.

School work is continued during the patient's stay in hospital and the hospital teacher keeps in contact with the school.

As the patient progresses he is introduced to a full-length mirror where he can have a critical look at his scarred body, especially his face. Later he meets the staff of the hospital by attending the week!y film show and eventually the public by going out to the hospital grounds. He should at all times be encouraged to talk about his scarred body and to express his feelings.
Parents: Need constant reassurance as they too may have guilt feelings perhaps because lack of proper supervision led to their child's injury. They may react by showing excessive sympathy or overprotection. Time will have to be spent with parents outlining the approach to treatment, the probable outcome, degree of scarring and the possible length of stay in hospital. All parents are referred to the Social Worker. It is advisable for parents of newly admitted children to speak to those of convalescent patients as they may be able to give comfort and emotional support from their own experience. Parents are encouraged to visit regularly and to keep in contact with the patient by sending cards and photographs of family and friends to show that they care. As the patient progresses, photographs are given to parents to take home to prepare family and friends for his return.

\section{Complications}

In lesser cases there may be some scarring, minor contractures or even loss of fingers, toes or hair. After major burns psycho-emotional trauma, and major contractures are common and even loss of limb(s) may occur. If infection occurs, the child may die.

\section{Advice on Discharge}

1. To attend regular follow-up clinic in out-patients department.

2. The importance of wearing the pressure garment correctly and for the required length of time.

3. To apply lanoline to the scarred skin to make the skin supple and soft.

4. To protect healed areas from the sun.

5. To recommence school attendance as soon as possible.

\section{Conclusion}

Successful treatment of the burnt child requires the combined efforts of doctors, nursing staff, physiotherapists, occupational therapists, social workers and school teachers the goal being the return of a functionally independent child to society.

Although we strive to provide the maximum care for our patients we must never lose sight of the old saying "Prevention is better than cure," and no effort must be spared to prevent this unnecessary, disfiguring and potentially fatal type of accident to any child. At Red Cross Children's Hospital, the Child Safety Centre is actively involved in programmes to educate the public regarding hazards to which children in our community are exposed.

I wish to thank Professor S Cywes, Department Paediatric Surgery and the Medical Superintendent, Dr W Greeff, for permission to publish this article. 